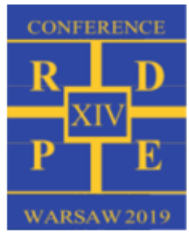

\title{
Fuel processing in a swirl flow: numerical modelling of combustion and gasification
}

\author{
Robert Zarzycki, Justyna Jędras, Rafał Kobyłecki \\ Czestochowa U niversity of Technology, ul. Dąbrowskiego 69, 42-201 Częstochowa, Poland; E-mail: robert.zarzycki@pcz.pl
}

\begin{abstract}
This study presents the concept of a cyclone furnace for coal dust combustion and gasification under conditions of oxy-fuel combustion. A two-chamber design of the cyclone furnace allows for the separation of the process of heating, drying and devolatilization of fuel from processes of its combustion and gasification of carbon residue. The choice of process parameters helps control fuel gasification. Supplying the driving gas with a specific composition $\left(\mathrm{O}_{2}, \mathrm{CO}_{2}\right)$ to the chamber $\mathrm{PC} 1$ ensures the control of temperature and composition of combustible gases obtained through gasification. These gases can be used as a fuel for power boilers and, consequently, allow for utilization of the oxy-fuel combustion technology in new or existing power boilers.
\end{abstract}

\section{Introduction}

The burning of fossil fuels in many countries is the main source of electricity and heat. The processes of fossil fuel combustion in conventional boilers (stoker boilers, direct flow boilers, or fluidized bed boilers) are already wellrecognized and no further significant development of these technologies is expected. Due to their negative impact on the natural environment, the use of fossil fuels in the power industry $\mathrm{CO}_{2}, \mathrm{SO}_{x}, \mathrm{NO}, \mathrm{Hg}, \mathrm{HCl}$ and dust emission) will be reduced in the coming years. The recently rising costs of $\mathrm{CO}_{2}$ emission allowances will limit the development of energy based on burning fossil fuels. However, it is planned to replace the processes of direct coal combustion with the processes of its gasification [1, 2]. A fter purification, the gas produced during coal gasification can be used as a substrate for various chemical processes or as a fuel.

\section{Cyclone furnace}

Cyclone furnaces are power-generating devices where fuel combustion and gasification processes occur in a strong swirl flow of gas [3 - 5]. With effective mixing and a relatively small combustion chamber in cyclone furnaces, it is possible to ensure combustion of solid, liquid and gaseous fuels. These fuels may also have low calorific value, with high ash and water contents. With a relatively high heat load in the combustion chamber, it is possible to implement the process of combustion and gasification, e.g. fragmented hard coal and black coal. A fter purification and preparation, gas obtained during gasification can be used as a substrate for various industrial purposes or for combustion in chambers of power boilers by replacing it by e.g. ignition fuel. Therefore, the gasification process in the atmosphere of air, oxygen, recirculated flue gas $\left(\mathrm{CO}_{2}\right)$ or water steam can be performed in a cyclone furnace. The present study discusses the results of computations for the process of coal dust gasification in the $\mathrm{O}_{2} / \mathrm{CO}_{2}$ atmosphere.

The cyclone furnace (Fig. 1) consists of two upper (PC2) and lower (PC1) chambers. The chamber PC2 is cylinder-shaped. Its upper part features tangentially designed channels used for pneumatic supply of fragmented fuel (coal dust). The upper part is equipped with a plunger used to limit the transport of fine coal dust grains outside the chamber PC2 to the chamber PC3 for combustion of gasification products. The lower chamber PC 1 is comprised of several steps with reduced diameters. Each step features tangential nozzles that allow for the supply of the "driving" gas with the specific composition $\left(\mathrm{O}_{2}, \mathrm{CO}_{2}\right)$ to the chamber PC1. B oth chambers (PC1 and $P C 2$ ) are connected with a channel where an internal plunger allows for separation of the flow of flue gas from the chamber PC1 to PC2 and the fuel flow (carbon residue) from the chamber PC 2 to PC 1 (Fig. 1). The lower part of the chamber PC 1 features an axially located nozzle for the supply of gases with specific composition to the chamber $\mathrm{PC}$.

The discussed design of a cyclone furnace containing two chambers allows for:

- heating, drying and gasification of fuel in the chamber PC2;

- coal gasification process in the atmosphere of recirculated flue gas $\left(\mathrm{CO}_{2}\right.$ and $\left.\mathrm{O}_{2}\right)$ or $\left(\mathrm{CO}_{2}, \mathrm{O}_{2}\right.$ and $\mathrm{H}_{2} \mathrm{O}$ ) in order to maximize production of $\mathrm{CO}$ and $\mathrm{H}_{2}$, as well as combustion of a certain part of carbon residue in order to generate the necessary amount of heat for maintaining and control over endothermic reactions. 


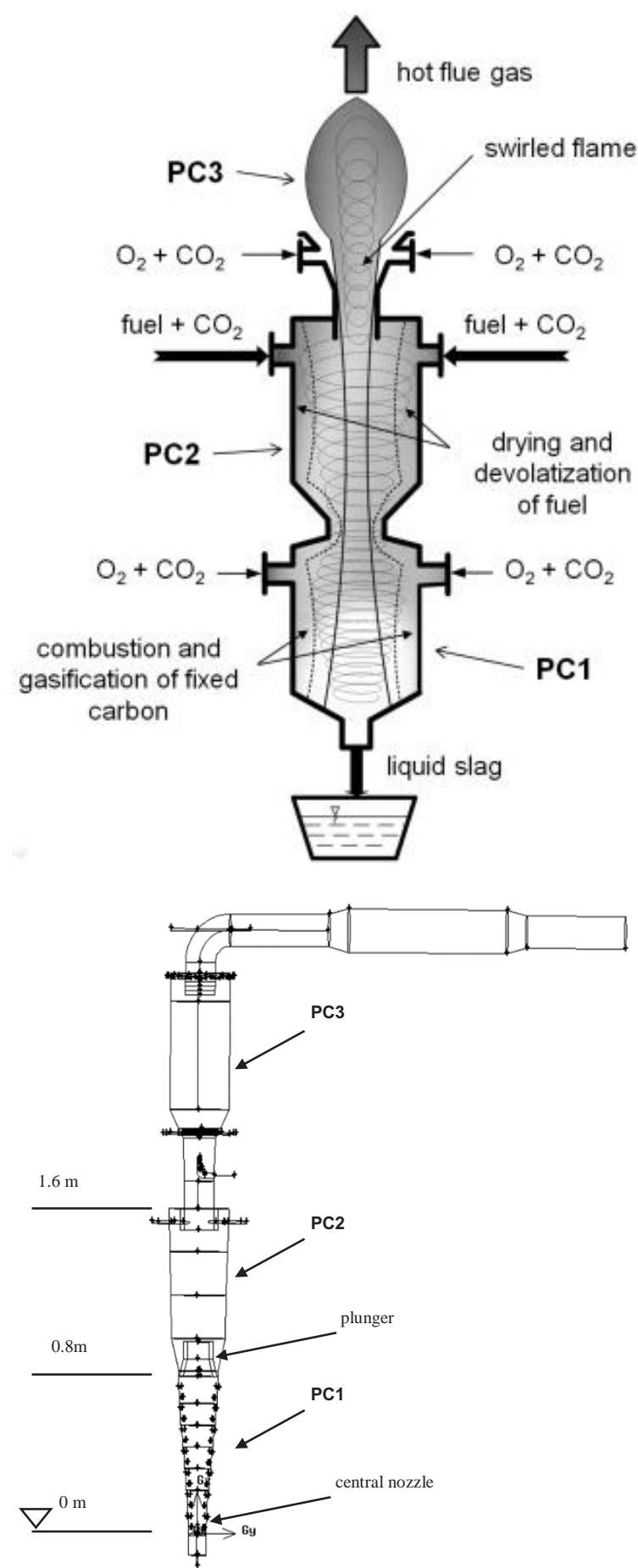

Fig. 1. The design and view of the geometry of a cyclone furnace.

\section{Modelling of the process of coal combustion and gasification in a cyclone furnace}

ANSY S FLUENT 14 software was used for calculations of the flow of coal dust and the combustion and gasification process. The numerical model of the process allows for the computation of coal dust gasification in the atmosphere of $\mathrm{O}_{2}, \mathrm{CO}_{2}$ through flue gas recirculation.

The lower part of the cyclone furnace (the chamber
PC1) (Fig. 1) features nozzles that allow for implementation of the driving medium with oxidant $\mathrm{O}_{2}$, $\mathrm{CO}_{2}$ ), whereas the upper part of the chamber $\mathrm{PC} 2$ contains inlets for coal dust through which the dust is supplied to a cyclone furnace pneumatically, using the stream of $\mathrm{CO}_{2}$. The central nozzle in the lower part of the chamber PC1 is used for supply the gas mixture to the chamber PC1 (e.g. $\mathrm{CH}_{4} / \mathrm{O}_{2}$ that allows for stabilization of the processes of gasification and combustion of carbon residue.

Calculations of gas and fuel flow were performed using the Reynolds Stressturbulence model [4,5], which can also be successfully used for strong swirl flow. Modelling of the flow of coal grains was based on the Discrete Phase Model, whereas coal dust combustion was performed using the Species Transport model, which allows for modelling chemical reactions both in the solid and gaseous phases [6-10]. The calculations were based on the radiation model termed Discrete Ordinate (DO). Calculations of the process of coal dust combustion and gasification with replacement diameter of $500 \mu \mathrm{m}$ were carried out for the fuel with physicochemical parameters as presented in Table 1. For simplification purposes, it was adopted that the fuel does not contain sulphur. Reaction rate constants were derived from the studies [6, 7].

Table 1. Result of technical and elemental analysis of the fuel used for simulations (dry state).

\begin{tabular}{|c|c|c|c|}
\hline $\begin{array}{c}\text { Proximate } \\
\text { analysis }\end{array}$ & {$[-]$} & $\begin{array}{c}\text { Ultimate } \\
\text { analysis }\end{array}$ & {$[-]$} \\
\hline VM & 0.45 & C & 0.85 \\
\hline FC & 0.45 & H & 0.1 \\
\hline A & 0.05 & O & 0.04 \\
\hline M & 0.05 & $\mathrm{~N}$ & 0.01 \\
\hline
\end{tabular}

Calculations for combustion and gasification of coal dust was described with seven reactions:

Reaction of volatile matter combustion

$$
\mathrm{x}_{1} \mathrm{VM}+\mathrm{x}_{2} \mathrm{O}_{2}=\mathrm{y}_{1} \mathrm{CO}+\mathrm{y}_{2} \mathrm{H}_{2} \mathrm{O}+\mathrm{y}_{3} \mathrm{~N}_{2}
$$

where: $x_{1}, x_{1}, y_{1}, y_{2}, y_{3}$ are stoichiometric coefficients.

Reaction of oxidation of carbon oxide

$$
\mathrm{CO}+0.5 \mathrm{O}_{2}=\mathrm{CO}_{2}
$$

Reaction of oxidation of fixed carbon (FC)

$$
\mathrm{C}_{(s)}+0.5 \mathrm{O}_{2}=\mathrm{CO}
$$

B oudouard $\odot$ reaction

$$
\mathrm{C}_{(s)}+\mathrm{CO}_{2}=2 \mathrm{CO}
$$

Synthesis of water gas

$$
\mathrm{C}_{(s)}+\mathrm{H}_{2} \mathrm{O}=\mathrm{CO}+\mathrm{H}_{2}
$$

Hydrogen oxidation reaction

$$
\mathrm{H}_{2}+0.5 \mathrm{O}_{2}=\mathrm{H}_{2} \mathrm{O}
$$

$M$ ethane oxidation reaction

$$
\mathrm{CH}_{4}+1.5 \mathrm{O}_{2}=\mathrm{CO}+2 \mathrm{H}_{2} \mathrm{O}
$$


Conditions of coal dust gasification process, which are the subject of numerical modelling were as follows: flow of coal dust with mean grain size of $500 \mu \mathrm{m}$ of $1 \cdot 10^{-3} \mathrm{~kg} / \mathrm{s}$ supplied tangentially with two inlets located at the opposite sides of the chamber PC2 (Fig. 1) in the $\mathrm{CO}_{2}$ stream at the rate of $3 \mathrm{~m} / \mathrm{s}$. Following a helical line, the fuel moves downwards in the chamber PC2 as it is heated, dried and devolatilized through the effect of hot flue gas that flows in the furnace axis and contact with hot walls of the chamber PC2. A fter devolatilization of the fuel, the process of partial burning of fixed carbon (FC) occurs in the chamber PC1. Through the set of feed nozzles for PC 1 chamber, the "driving" gas was tangentially fed to the one forming the "driving" gas at the rate of $3 \mathrm{~m} / \mathrm{s}$ and temperature of $600 \mathrm{~K}$ with molar fraction of $\mathrm{O}_{2} / \mathrm{CO}_{2}$ $40 / 60 \%$. Introduction of the driving gas supplied tangentially from the nozzles in the chamber PC1 is necessary to maintain proper conditions of the swirl flow of the coal dust. The lower part of the chamber PC1 features an additional central nozzle (located axially), from which the mixture of gases $\left(80 \% \mathrm{O}_{2}, 20 \% \mathrm{CH}_{4}\right)$ at a temperature of $350 \mathrm{~K}$ was discharged at a constant rate of $10 \mathrm{~m} / \mathrm{s}$.

The numerical model also takes into consideration the heat transfer through furnace walls to its surroundings. Calculation of heat loss took into consideration the actual thickness of individual components of the laboratory furnace $[4,5]$ with coefficients of heat penetration and conduction for the materials used. It was assumed that air temperature around the furnace is $300 \mathrm{~K}$.

\section{Analysis of the process of coal dust combustion and gasification}

A nalysis of the distribution of selected process parameters in two perpendicular cross-sections of the cyclone furnace. Distributions of fuel concentration on internal walls of the cyclone furnace are presented in Fig. 2a, whereas vertical cross-sections in two perpendicular planes are presented in Fig. 2b. As expected, the results show that the fuel, which was supplied in the upper part of the chamber PC2 as a result of strong swirl flow and effect of the centrifugal force, moves only near the internal walls of the furnace (Fig. 2b). For the adopted process conditions, the highest concentration of fuel in the upper part of the $\mathrm{PC} 1$ chamber occurs in the vicinity of its walls.

Fig. $2 c$ shows the distribution of the combustion rate for the devolatilized fuel (fly ash). It is noticeable that the area of the highest combustion rates is located in the upper part of the PC1 chamber (near the symmetry axis) and coincides with the area of decreasing fuel concentration in Figs. $2 \mathrm{a}$ and $2 \mathrm{~b}$.

The consequence of the high fuel combustion rate is temperature distributions shown in Fig. $2 \mathrm{~d}$ near the inner walls of the furnace and in Fig. $2 \mathrm{e}$ in the vertical crosssection of the cyclone furnace. Analysis of Figs. $2 d$ and 2e reveals a high-temperature region exceeding $2000 \mathrm{~K}$ in the upper part of the $\mathrm{PC} 1$ chamber. It is directly related to the burning of fuel in the form of fly-ash. In the lower part of the PC1 chamber (Fig. 2e), the area of high temperatures exceeding $2000 \mathrm{~K}$ is also observed, coinciding with the location of combustion of the $\mathrm{CH}_{4} / \mathrm{O}_{2}$ mixture supplied from the central nozzle.

The combustion or gasification process depends on the presence of fuel and oxygen concentration. Fig. $2 f$ presents distributions of molar fractions of oxygen in the vertical cross-section of the cyclone furnace. In order to reduce the loss of incomplete combustion at the design stage, it was assumed that the lower part of the PC1 chamber should have the highest possible oxygen concentration. This can be achieved by supplying excess oxygen in the $\mathrm{O}_{2} / \mathrm{CH}_{4}$ mixture through a burner installed in the lower part of the PC1 chamber. A nalysis of the distributions of oxygen concentration presented in Fig. $2 f$ reveals that the oxygen concentration in the lower part of the PC1 chamber exceeds $30 \%$ (for the accepted process conditions). These conditions allow for minimizing the loss of incomplete combustion. The upper part of the PC 1 chamber shows an oxygen concentration close to zero. The area in which there is a rapid decline in oxygen concentration coincides with the location of the highest temperatures (Fig. 2e), high rates of fly ash combustion (Fig. 2C), which indicates the location of the front of fuel combustion in this place. In this area, significant amounts of heat are released, which results in a large surface and volume load to the $\mathrm{PC} 1$ chamber. Due to the properties of the materials used in the construction of the fireplace, it is not recommended to further increase the temperature. It is necessary to control the temperature, which can be achieved e.g. by reducing the fuel flow and heat generation. Temperature can also be controlled by means of an endothermic $B$ oudouard reaction. In order to ensure the effectiveness of the gasification process in accordance with the Boudouard reaction, it is necessary to meet several conditions of the process. This process takes place at sufficiently high temperatures. At temperature above $900 \mathrm{~K}$, the balance of Boudouard $\mathrm{s}$ reaction is shifted towards carbon monoxide formation. The Boudouard reaction is only possible with the presence of reactive fixed carbon (devolatilized fuel i.e. fly ash) and sufficient time for the fixed carbon to react with carbon dioxide, and the most intensive contact of fixed carbon and carbon dioxide. These conditions are ensured by the design of the PC1 chamber of the furnace in which a stream of strong swirl flow of coal dust devolatilized in the PC2 chamber, transported through individual steps of the PC1 chamber, allows for virtually infinite contact of fuel with carbon dioxide, which is supplied as one of the components of the "driving" gas (flue gas recirculation) and is a product of fixed carbon combustion. In this case, it is only important to ensure a sufficient temperature to initiate and then continue the B oudouard reaction.

The distributions of $\mathrm{CO}_{2}$ and $\mathrm{CO}$ concentrations in the vertical cross-sections of the furnace are shown in Figures $2 \mathrm{~g}$ and $2 \mathrm{f}$, respectively. It is noticeable that in the lower part of the PCl chamber, the $\mathrm{CO}_{2}$ concentration is ca. $60 \%$, which is related to the supply of the "driving" gas 
with the assumed composition of $\mathrm{O}_{2} / \mathrm{CO}_{2}$ of $40 / 60 \%$. In the central part of the $\mathrm{PCl}$ chamber, the $\mathrm{CO}_{2}$ concentrations increase locally, which is associated with the combustion of fly ash (location of the combustion front) and then it declines quite rapidly. Furthermore, the analysis of the $\mathrm{CO}$ concentrations presented in Figure $2 \mathrm{~h}$ reveals concentrations of this component in the lower part of the PC1 chamber close to zero (due to the excess oxygen occurring there, see Fig. 2f), while a rapid increase in $\mathrm{CO}$ concentration occurs above the place identified as the fly ash combustion front. This increase is caused by the presence of devolatilized fuel (Figs. $2 a$ and $2 \mathrm{~b}$ ), high temperatures above $2000 \mathrm{~K}$ (Figures $2 \mathrm{~d}$ and $2 \mathrm{e}$ ), low oxygen concentration (Fig. 2f) and high concentration of $\mathrm{CO}_{2}$ (Figures $2 \mathrm{~g}$ ). Compliance with these conditions allows for fuel gasification in accordance with the B oudouard reaction (4).

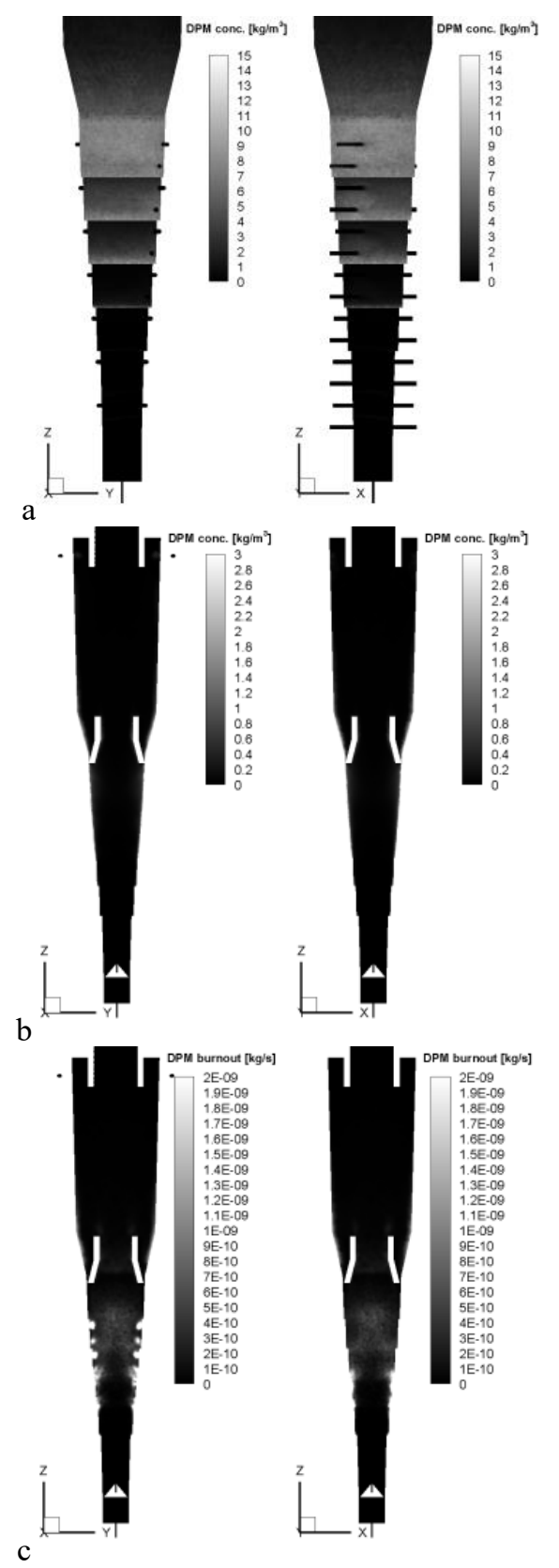

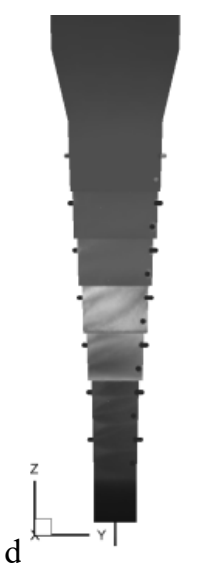
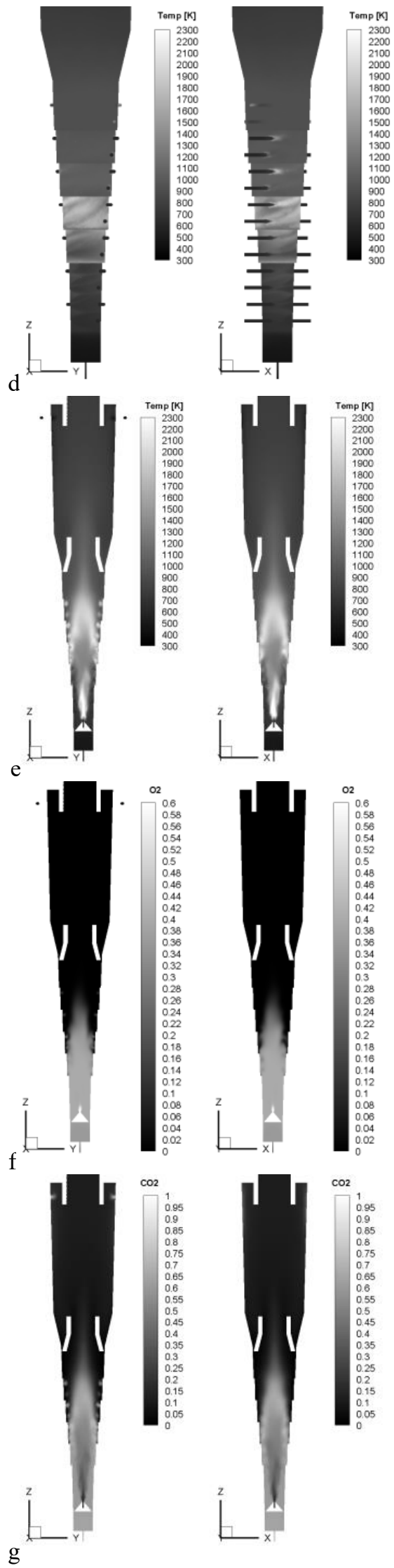


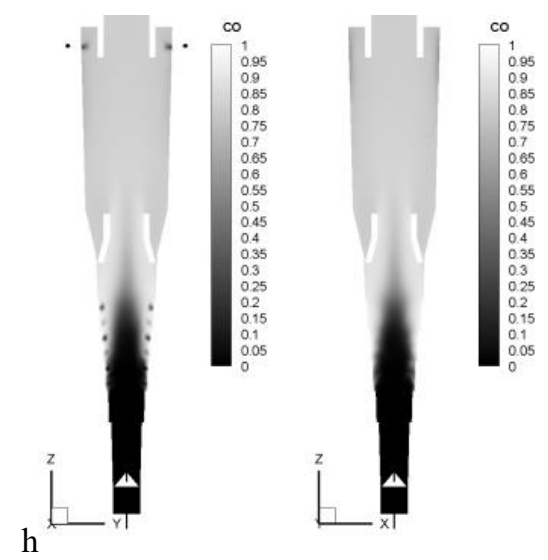

Fig. 2. Distributions of selected values for gas supplied by "driving" nozzles of the $\mathrm{PC} 1$ chamber with composition of $40 \% \mathrm{O}_{2}, 60 \% \mathrm{CO}_{2}$ : a) fuel concentration on the furnace walls, b) fuel concentration in the vertical section of the furnace, c) combustion rate for the devolatilized fuel (fly ash), d) temperature near the furnace walls, e) temperature in the vertical section of the furnace, $\mathrm{f}$ ) molar fractions of $\mathrm{O}_{2}$ in the vertical section, g) molar fractions of $\mathrm{CO}_{2}$ in the vertical section of the furnace, h) molar fractions of $\mathrm{CO}$ in the vertical section.

Table 2 presents selected mean process parameters at the outlet from $P C 1$ and $P C 2$ chambers. The temperature drop between PC1 and PC2 cross-sections can be observed. It results from the process of heating and degassing of the fuel in the PC2 chamber and supplying of a $\mathrm{CO}_{2}$ stream into the $\mathrm{PC} 2$ chamber, transporting pneumatically the fuels at a temperature of $300 \mathrm{~K}$. For the assumed process parameters, the $\mathrm{O}_{2}$ concentration at the outlet from the PC1 and PC2 chambers is close to zero. A nalysis of the $\mathrm{CO}_{2}$ and $\mathrm{CO}$ concentrations at the outlet from the PC1 chamber reveals the effect of the coal gasification process. At the outlet from the $\mathrm{PC} 1$ chamber, the $\mathrm{CO}$ concentration of 0.859 and the $\mathrm{CO}_{2}$ concentration of 0.071 are obtained for the adopted process conditions. $M$ inor changes in concentrations are noticeable at the outlet from the PC2 chamber and result mainly from the dilution of the gas generated in the process of gasification with carbon dioxide used for pneumatic fuel supply to the PC2 chamber. The function of the PC2 chamber as a fuel degassing area is confirmed by the values of volatile matter (V M ) concentrations. Despite the dilution of the gases in the $\mathrm{PC} 2$ chamber with $\mathrm{CO}_{2}$ supplied with the fuel, the V M concentration increases to 0.064 .

Table 2. Selected process parameters at the outlet from the PC1 and PC2 chambers.

\begin{tabular}{|l|l|l|}
\hline & PC1 & PC2 \\
\hline Temp $[\mathrm{K}]$ & 978.2 & 767.2 \\
\hline $\mathrm{O}_{2}[-]$ & $4.22 \mathrm{E}-05$ & $1.05 \mathrm{E}-19$ \\
\hline $\mathrm{CO}_{2}[-]$ & 0.071 & 0.114 \\
\hline $\mathrm{CO}[-]$ & 0.859 & 0.805 \\
\hline $\mathrm{VM}[-]$ & 0.053 & 0.064 \\
\hline
\end{tabular}

\section{Conclusions}

The results of numerical modelling of coal dust gasification and combustion in an innovative cyclone furnace lead to the following conclusions:

- The configuration of the geometry of the lower part of the furnace and distribution of the "driving" nozzles at individual levels helps control the time of fuel grains (fly ash) remaining so that the maximal level of its reaction is achieved.

- The process of fuel devolatilization and its gasification as a result of the Boudouard reaction allows for controlling the temperature inside the PC 1 chamber.

- For the adopted conditions of cyclone furnace operation, the $\mathrm{CO}$ concentrations at the outlet from the chamber PC2 were ca. $80 \%$.

The results presented in the paper were obtained in a project cofinanced by NCBR within the contract No. BIOSTRATEGG3/345940/7/ NCBR/2017 titled Water in soil: satellite monitoring to improve water retention using biochar (project acronym: SoilA qChar). The paper was co-financed by BS/PB-400-301/19.

\section{References}

1. Zhao Y., Feng D., Sun S., Luan J., Che H., Characteristics of rice husk gasification in cyclone pyrolysis-suspended combustion system, Thermal Science, vol. 22, Suppl. 2, pp. S439-S447, (2018).

2. Osborne D., The Coal Handbook: Towards Cleaner Production: Volume 2: Coal Utilisation, Woodhead Publishing, (2013).

3. Guo J., Zhang L., Cang D., Zhang C., W ang D., Y in $H$., Cold experimental studies of flow field in the swirling coal combustion device, IOP Conf. Series: Earth and Environmental Science, vol. 94, pp.012021, (2017).

4. Zarzycki R., Bis Z., Kobyłecki R., The Concept of Coal Burning in a Cyclone Furnace, Procedia Engineering, V ol. 157, pp. 472-479, (2016).

5. Zarzycki R., Bis Z., M odelling of the process of coal dust combustion in a cyclone furnace, Journal of Thermal Science, vol. 26, Issue 2, pp 192-198, (2017).

6. Toporov D., Bocian P., Heil P., Kellermann A., Stadler H., Tschunko S., Förster M., Kneer R., Detailed investigation of a pulverized fuel swirl flame in C02/02 atmosphere. Combustion and Flame, vol. 155, pp. 605-618, (2008).

7. Vascellari M., Cau G., Numerical simulation of pulverized coal oxycombustion with exhaust gas recirculation. Proceeding of CCT2009 Fourth International Conference on Clean Coal Technologies. Dresden, Germany, (2009).

8. Chen L., Gazzino M ., G honiem A .F ., Characteristics of pressurized oxy-coal combustion under increasing swirl number. 35th International Technical Conference on Coal Utilization \& Fuel Systems. Clearwater, Florida, (2010).

9. Warzecha, P. ,Bogusławski, A., Symulacje numeryczne spalania pyłu węglowego w atmosferze 
02-C02. Archiwum Spalania, vol. 12, No. 3, pp.

145-151, (2012).

10. AN SY S Fluent Theory Guide, (2011). 